\title{
Turnover Based Illiquidity Measurement as Investment Strategy on Zagreb Stock Exchange
}

\author{
Jelena Vidović \\ University Centre for Professional Studies, Split, Croatia \\ Email: jvidovic@oss.unist.hr
}

How to cite this paper: Vidović, J. (2020) Turnover Based Illiquidity Measurement as Investment Strategy on Zagreb Stock Exchange. American Journal of Operations Research, 10, 1-12.

https://doi.org/10.4236/ajor.2020.101001

Received: November 8, 2019

Accepted: December 3, 2019

Published: December 6, 2019

Copyright $\odot 2020$ by author(s) and Scientific Research Publishing Inc. This work is licensed under the Creative Commons Attribution International License (CC BY 4.0).

http://creativecommons.org/licenses/by/4.0/

\begin{abstract}
This paper deals with illiquidity measurement of stocks on Croatian Stock market. Illiquidity measures used in this paper are daily ratio of absolute stock return to its dollar volume (ILLIQ) and RCT (Relative change in turnover). Aim of this paper is to show that illiquidity measure RCT makes clear distinction between liquid and illiquid stocks that should be reflected through investment strategy where investment in RCT based illiquid portfolios outperforms investment in ILLIQ based portfolios and CROBEX index. Research was carried out on eighteen stocks from Zagreb Stock Exchange (ZSE) which are constituents of CROBEX index. Portfolios of liquid and portfolios of illiquid stocks based on results of illiquidity measurement were constructed. Behaviour in terms of return and volatility of these portfolios in following one-year period was observed. Results showed that portfolios formed using RCT as measure of illiquidity constantly outperformed CROBEX index and ILLIQ based portfolios. Returns of RCT based portfolios had lower standard deviation and were more stable than ILLIQ based portfolios in whole period. RCT as a measure of illiquidity produces valuable information on stock liquidity that can be exploited as investment strategy reflecting itself in larger expected returns of RCT portfolios in future period than expected returns of ILLIQ based portfolios and market.
\end{abstract}

\section{Keywords}

Illiquidity Measure, Investment, Portfolio, Stock, Turnover

\section{Introduction}

Illiquidity is proven attribute of stocks, it has strong impact on assets pricing, portfolio selection and risk management. Academic discussion in the past forty years did not give the answer to the best illiquidity measure. Illiquidity should 
reflect itself in higher expected returns of stocks which are recognized to be illiquid compared to other stocks. There are several approaches to illiquidity measurement: measures calculated from daily stock data and finer measures of illiquidity, such as the bid ask spread which requires data on transactions and quotes which are sometimes unavailable for all markets. In academic papers, one of the most accepted measures of illiquidity is ILLIQ [1] calculated from data on daily stock returns and volume which can be easily obtained. ILLIQ is most recognized illiquidity measure but still is not recognized as the all-purpose illiquidity measure for both developed and underdeveloped markets. Another readily available measure is trading volume which is a natural measure of stock liquidity. Return is negatively related to the stock (dollar) volume, and volume subsumes the negative effect of size [2]. Some authors argue that expected return in developed markets is a function of volatility [3], while others argue a positive relation between volatility and market thinness or illiquidity [4] and [5].

This paper follows recent discussion on illiquidity measurement on Zagreb Stock Exchange. Reference [6] proposed new illiquidity measure RCV (Relative change in volume). RCV was applied as measure of illiquidity on Johannesburg Stock Exchange and results showed that portfolios selected based on RCV as measure of illiquidity outperformed portfolios based on ILLIQ and all the other observed measures in the whole period [7]. What is more important, performance of these portfolios was stable to the whole period-or simply said portfolios did not show any sudden declines. In this paper RCV was redefined and applied on Croatian Stock Market.

The paper is organized as follows: in the second part of the paper previous researches on liquidity of Croatian Stock Market, in the third part of the paper data and methodology are explained measures of illiquidity Relative Change in Turnover (RCT) and ILLIQ are defined. Based on RCT and ILLIQ portfolios of illiquid and liquid stocks were formed and their returns in following one year period were observed. In the fourth part of the paper results are presented and in the last part of paper, the most important results are outlined and guidelines for further research are given.

\section{Literature Review}

Previous literature generally recognizes two large groups of liquidity measures; that are trade based and order based measures. Trade based measures include trading volume [2] and the turnover ratio (TURN) as the ratio of trading volume to the number of shares outstanding [8]. These measures are attractive as they can be easily calculated using available data on stock prices and traded volume. Order based measures are based on the more detailed trading data like data from order book. According to findings of [9] there is a little correlation between trade based and order based measures. They suggested that the choice of measure may have a significant effect on research outcomes and therefore policy decisions [10]. Reference [8] proved strong negative relation between stock returns and turnover rates (number of shares traded as a fraction of the number of shares 
outstanding) confirming that illiquid stocks provide higher average returns for non-financial firms from the NYSE. Reference [1] observed average ratio of the daily absolute return to the dollar trading volume on that day for the U.S. market. Author concluded that stock illiquidity affects strongly firms with smaller market capitalization. Others noticed that local market liquidity is important driver of expected returns in emerging markets [11]. They found no pattern in the correlation between estimates of conditional volatility and the liquidity measure. Reference [3] measured portfolio liquidity by turnover ratio computed as value of shares traded over the market capitalization. Evidence were found that significantly increasing relation between turnover and return is true exclusively for the emerging markets, and that developed markets show a significant relation between return and volatility but not between turnover and return. Reference [11] concluded that longer periods of consecutive non-trading are associated with greater illiquidity effects. They employed the Zero measure [12] which is simply the proportion of zero daily returns averaged over moths. Their measure attempts to take return catch up effect into account. According to [5] Zeros can be defined as a measure of market thinness which should be positively related to volatility.

Illiquidity is more obvious on underdeveloped markets such as Croatian. Reference [13] reported substantial level of illiquidity on the Croatian and other developing markets. They observed several liquidity measures and concluded that ILLIQ is not suitable for developing markets.

Measurement of liquidity on Croatian stock market showed that large companies (according to market capitalization) are more liquid than companies with lower market capitalization [14]. Stocks that had larger traded volume in 2010 had greater market liquidity or depth. Reference [15] applied simple naïve portfolio diversification in forming liquidity-sorted portfolios. Illiquidity was measured using ILLIQ. Existence of illiquidity premium on eight Central and South East European stock markets was not confirmed. Frontier markets remain low liquid despite their constant improvements and development [16]. It is noticed that the sample and liquidity proxy used determines the preciseness of liquidity risk measurement. Testing standard and Liquidity CAPM (LCAPM) on Croatian stock market for the period from 2005-2009 showed that LCAPM performs better in explaining stock returns than the CAPM [17]. Authors assumed that classical CAPM does not capture liquidity risk that is the key problem on such small and underdeveloped markets. Reference [18] performed empirical analysis of liquidity for the Croatian stock market. For this analysis three measures were used: Zero Rates returns, Price Pressure, and turnover. Author concluded that that the level of liquidity for the Croatian market is very low. Reference [7] employed liquidity based investment style on the Johannesburg Stock Exchange by forming liquidity based portfolios. Results showed that portfolios formed by using Relative Change in Volume [6] as a measure of illiquidity have consistently outperformed the market over time both in a short-term and long-term.

Above mentioned authors proved existence of illiquidity on the Croatian stock 
market but could not point out or introduce the best illiquidity proxy. General thinking on liquidity generally relies on price/volume/number of shares outstanding/volatility/number of trading days relation. This especially becomes evident on underdeveloped markets such as Central and South East European markets were investors are exposed to infrequent trading, extreme returns and higher level of risk [19]. Illiquidity measure should produce information on stock/stocks that in future period could give higher returns. Analysis in this paper follows that idea questioning what illiquidity measure points out stocks that could give excess return.

\section{Methodology}

Data for this study are obtained from Zagreb Stock Exchange and include information on stock returns and traded volumes for 18 stocks that are constituents of CROBEX-Zagreb Stock Exchange equity index. Daily data are gathered for the period starting from beginning of June of 2016 to the end of May of 2018.

In the first part of the analysis values of ILLIQ on RCT for each stock for period from beginning of June 2016 to the end of May of 2017 were calculated. In the second part of analysis equally weighted portfolios were constructed based on results on ILLIQ and RCT. Portfolios were composed in two sizes: 1) portfolio of 5 stocks (each stock takes $20 \%$ of weight in portfolio) and 2) portfolio of 10 stocks (each stock takes $10 \%$ weight in portfolio). Portfolios were constructed in two scenarios: 1) portfolio of 5 and 10 most liquid stocks (minimum RCT values and minimum ILLIQ values) and 2) portfolios of 5 and 10 most illiquid stocks (maximum ILLIQ measure and maximum RCT measure). Created portfolios were not rebalanced at any time and no additional filters were used. In the final part of analysis portfolio returns were observed in period from the beginning of June 2017 to the end of May 2018. Hypothesis is that portfolios of 5 and 10 illiquid stocks overperforme CROBEX index in one of these two cases: 1) when portfolio is composed based on observation of illiquidity using ILLIQ and 2) when portfolio is composed based on observation of illiquidity using Relative Change in Turnover (RCT).

ILLIQ [1] is defined as the ratio between the absolute return over dollar volume.

$$
\operatorname{ILLIQ}_{i}=\frac{1}{I} \sum_{t=1}^{I}\left|R_{i t}\right| / V_{i t} P_{i t}
$$

where $R_{i t}$ is the daily return on stock $i$ on day $t, V_{i t}$ is the respective daily volume, $P_{i t}$ is the price of stock $i$ on day $t$ and $I$ is the number of days for which data are available for stock $i$. In literature ILLIQ is often referred as measure of price impact (PI). Daily return is calculated in continuous time:

$$
R_{i t}=\ln \left(P_{i t} / P_{i, t-1}\right)
$$

This measure captures the intuition that a security is less liquid if a given trading volume generates a greater move in its price. High value of ILLIQ indicates illiquidity of a stock. Security is less liquid if a given trading volume gener- 
ates a greater move in its price. In other words, a stock is more liquid when it has a lower value of ILLIQ. The illiquidity of stock $i$ on $t$ day is measured by ILLIQ and is averaged over a 12-month period ending May 2017. Results on ILLIQ and RCT are reported in Table 1 and used in forming equally weighted portfolios.

References [6], and [20] proposed Relative Change in Volume (RCV) a solution that should capture and measure illiquidity on emerging markets. Relative Change in Volume is a trade-based measure designed to take into account the pressure of large differences in traded volume on return. In case of illiquid stocks it can be seen either small number of trading days or illiquidity caused by small daily volumes [6]. The most significant positive value produced by the formula represents the illiquid stock while the smallest value represents a highly liquid stock. The logic is that a highly liquid and frequent trading stock will always produce a smaller change in volume than the average volume traded, therefore resulting in a smaller RCV ratio. RCV looks at the changes in volume irrespective of what the share price is [7]. In this paper new definition of RCV was applied where volume was replaced with turnover.

Table 1. Results for RCT and ILLIQ for 18 stocks from CROBEX index in period from June 2016 ending May 2017.

\begin{tabular}{|c|c|c|c|c|c|}
\hline Stock & $\begin{array}{l}\text { Number of } \\
\text { trading days }\end{array}$ & $\begin{array}{l}\text { Expected } \\
\text { return }\end{array}$ & $\mathrm{RCT}$ & ILLIQ $^{\mathrm{a}}$ & $\begin{array}{l}\text { St. deviation of } \\
\text { return }\end{array}$ \\
\hline HT & 252 & 0.00081 & 0.8043 & 0.0069 & 0.0093 \\
\hline ARNT & 240 & 0.00173 & 1.0749 & 0.4785 & 0.0203 \\
\hline ZABA & 233 & 0.00074 & 1.1916 & 0.7593 & 0.0236 \\
\hline VLEN & 189 & 0.00138 & 1.1049 & 10.2062 & 0.0561 \\
\hline RIVP & 252 & 0.00219 & 0.7183 & 0.0104 & 0.0138 \\
\hline PODR & 249 & -0.00026 & 0.9639 & 0.3050 & 0.0143 \\
\hline OPTE & 252 & 0.00219 & 0.7183 & 0.0104 & 0.0138 \\
\hline MAIS & 195 & 0.00142 & 1.2769 & 0.9880 & 0.0236 \\
\hline KRAS & 238 & 0.00022 & 0.9518 & 0.3318 & 0.0150 \\
\hline KOEI & 205 & 0.00061 & 1.3609 & 0.9139 & 0.0176 \\
\hline INGR & 238 & 0.00271 & 0.9140 & 6.5727 & 0.0380 \\
\hline ERNT & 251 & 0.00062 & 0.8757 & 0.1177 & 0.0136 \\
\hline DLKV & 251 & 0.00203 & 0.7593 & 1.4375 & 0.0294 \\
\hline DDJH & 251 & -0.00043 & 0.8815 & 0.6531 & 0.0337 \\
\hline ATPL & 241 & 0.00456 & 0.7909 & 1.4093 & 0.0369 \\
\hline ATGR & 243 & -0.00025 & 1.1997 & 0.1703 & 0.0124 \\
\hline ADRS2 & 248 & 0.00084 & 1.0843 & 0.0453 & 0.0110 \\
\hline ADPL & 238 & 0.00180 & 0.9408 & 0.3720 & 0.0156 \\
\hline
\end{tabular}

a. ILLIQ is multiplied with $10^{6}$. 
Proposed improvement of RCV is Relative change in turnover (RCT). Turnover data are readily available on Zagreb Stock Exchange (ZSE) and are calculated as number of shares traded on observed day multiplied with average price on the same day. This measure is based on the previous conclusions that stock returns are negatively related to their turnover [8]. Additional problem that is noticed on underdeveloped markets is inconsistency of trading and large differences (positive or negative jumps) in traded volumes [3] [6] [11] and [20]. Previous researches did not give the answer on the best illiquidity proxy for Croatian stock market [13] [15] and [16]. ILLIQ and TURN produce opposite conclusions on stocks liquidity on Central and South-East European stock markets [20]. Larger traded volumes are connected with liquidity [14].

RCT observes changes in turnover in observed period over trading volume in that period. This formulation of RCT produces several information:

- Larger RCT indicates inconsistent trading and large unexpected variations in traded volume;

- As changes in turnover are divided with turnover of single stock in observed period, RCT enables comparison of illiquidity level among different stocks;

- Stocks that have larger traded volume during year have greater market liquidity.

The more the traded volumes and prices between two trades are different; the value of RCT will be higher. If this is accompanied with smaller traded value in observed period, it indicates grater pressure on stock price/return.

RCT is measured as sum of absolute daily changes in turnover over total turnover in observed period $I$.

$$
\operatorname{RCT}_{i}=\sum_{t=1}^{I} \frac{\left|V_{i t} \cdot P_{i t}-V_{i, t-i} \cdot P_{i, t-1}\right|}{V_{i t} \cdot P_{i t}}
$$

$V_{i t}$ is traded volume of stock ion day $t, P_{i t}$ is average price of stock $i$ on day $t$, and $I$ is number of trading days in observed period. Observed period in this case is from the beginning of June 2016 until the end of May of 2017. Average value of liquidity measure over one-year period was previously used in [1].

RCT is very easy to calculate from the daily data on traded volume and stock price in observed period. It has the ability to take into account the pressure of large differences in turnover on returns, problem that often occurs on underdeveloped markets. A liquid stock tends to have a small difference between $t$ and $t-1$ turnover in comparison to average traded volume in that period. The more the traded volumes and prices between two trades are different; the value of RCT will be higher. RCT above 1 simply says that there is inconsistency in trading, that large transactions appear occasionally, that these differences in traded volume on average in observed period are larger than average trading volume and that it could result in greater pressure on stock price/return. The higher the average turnover, the more price change can be absorbed without large impact on price therefore high RCT implies illiquidity. 
Based on results on ILLIQ and RCT portfolios of liquid and illiquid stocks were constructed and their behaviour in terms of return and volatility in following one-year period was observed. Estimated portfolios were analysed in out-of-sample period from June 2017 until end of May 2018. For each estimated portfolio, Cumulative Abnormal Returns (CAR-s) against CROBEX-The Zagreb Stock Exchange equity index were calculated. Standard event study methodology was used; abnormal daily returns of each portfolio against CROBEX index were calculated:

$$
A R_{i t}=r_{i t}-r_{m t}
$$

where $r_{i t}$ is daily return $(t)$ for portfolio $i$ and $r_{m t}$ is the appropriate benchmark return (CROBEX return).

CARs from the beginning of the first day until the last day of trading are the summation of abnormal returns.

$$
\mathrm{CAR}_{t}=\sum_{t=1}^{S} A R_{t}
$$

CARs were estimated assuming benchmark was the portfolio's normal return.

\section{Results}

In this paper 18 stocks that are in composition of CROBEX index in period from the beginning of June 2016 until the end of May of 2017 were observed. Stocks and their symbols are listed in Appendix.

Based on data from Table 1 portfolios of liquid and portfolios of illiquid stocks were composed. In Table 2 composition of portfolio of ten most illiquid stocks according to RCT and portfolio of ten most illiquid stocks according to ILLIQ is given: in left section along with portfolio expected returns and standard deviation of portfolio returns; in right section the same is given for liquid stocks. Portfolio returns were calculated in period from June 2017 until end of May 2018. Results on expected portfolio returns and standard deviation of portfolio returns are given in Table 2. Weight of each stock in portfolio is $10 \%$.

According to results on expected portfolio returns it can be seen that only RCT based portfolio of illiquid stocks had positive return and outperformed CROBEX index and ILLIQ based portfolios. Return of CROBEX index in the same period was -0.00005 and standard deviation of CROBEX return was 0.00523. ILLIQ based portfolios both liquid and illiquid had worse expected returns than CROBEX index.

Results from Table 3 on portfolios of five stocks confirm results based on observing portfolios of ten stocks. Again, RCT based portfolio of illiquid stocks had positive return and outperformed CROBEX index and ILLIQ based portfolios. Weight of each stock in portfolio in this case is $20 \%$.

Another conclusion from Figure 1 and Figure 2 can be drawn; returns of RCT illiquid portfolio are more stable than returns of ILLIQ based portfolios. Further in Table 2 and Table 3 it can be seen that standard deviation of RCT illiquid portfolios had smaller standard deviation than ILLIQ based portfolios of illiquid stocks. 


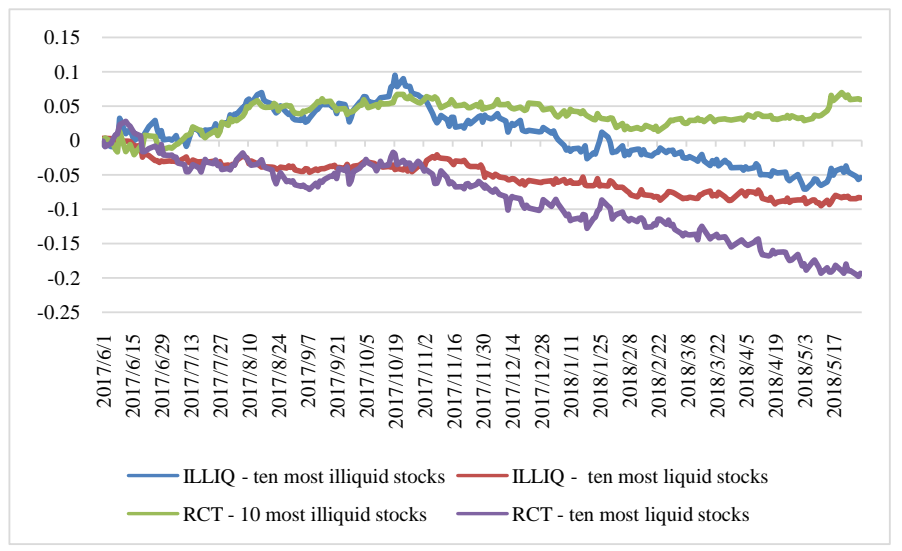

Figure 1. CARs of portfolios composed of ten stocks in period from June 2017 until end of May 2018.

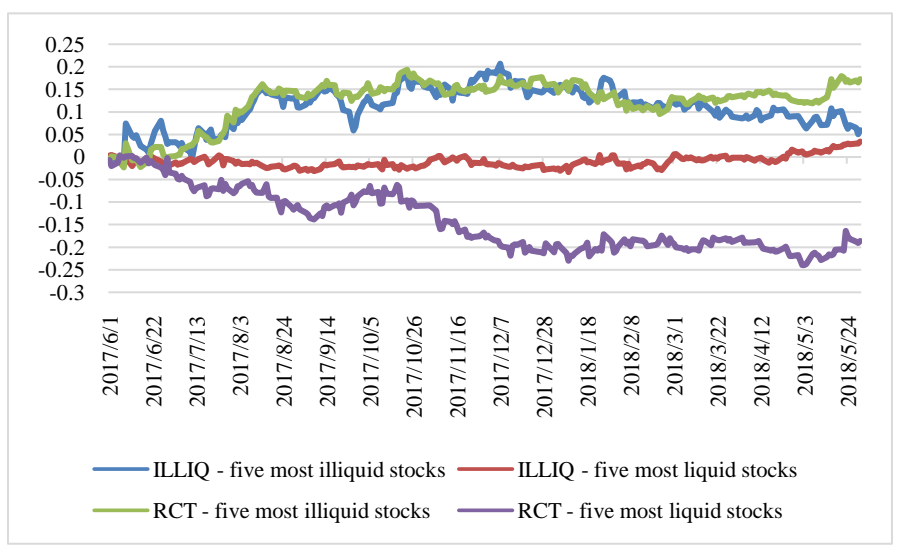

Figure 2. CARs of portfolios composed of five stocks in period from June 2017 ending May 2018.

Table 2. Composition of portfolios.

\begin{tabular}{ccccc}
\hline & \multicolumn{2}{c}{ Portfolioof top ten illiquidstocks } & \multicolumn{2}{c}{ Portfolioof top ten liquidstocks } \\
\cline { 2 - 5 } & $\begin{array}{c}\text { RCT-10 most } \\
\text { illiquidstocks }\end{array}$ & $\begin{array}{c}\text { ILLIQ-ten most } \\
\text { illiquidstocks }\end{array}$ & $\begin{array}{c}\text { RCT-ten most } \\
\text { liquidstocks }\end{array}$ & $\begin{array}{c}\text { ILLIQ-ten most } \\
\text { liquidstocks }\end{array}$ \\
\cline { 2 - 5 } & KOEI & VLEN & KRAS & ARNT \\
& MAIS & INGR & ADPL & ADPL \\
& ATGR & DLKV & INGR & KRAS \\
& ZABA & ATPL & DDJH & PODR \\
& VLEN & MAIS & ERNT & ATGR \\
& ADRS2 & KOEI & HT & ERNT \\
& ARNT & ZABA & ATPL & ADRS2 \\
PODR & DDJH & DLKV & RIVP \\
$\begin{array}{c}\text { Expected } \\
\text { portfolio return }\end{array}$ & KRAS & ARNT & RIVP & OPTE \\
$\begin{array}{c}\text { Standard } \\
\text { deviation of }\end{array}$ & ADPL & ADPL & OPTE & HT \\
\hline portfolio return & 0.00019 & -0.00026 & -0.00082 & -0.00038 \\
& & & & \\
\hline
\end{tabular}


Table 3. Composition of portfolios.

\begin{tabular}{|c|c|c|c|c|}
\hline & \multicolumn{2}{|c|}{ Portfolio of top five illiquid stocks } & \multicolumn{2}{|c|}{ Portfolio of top five liquid stocks } \\
\hline & $\begin{array}{l}\text { RCT }-5 \text { most } \\
\text { illiquid stocks }\end{array}$ & $\begin{array}{l}\text { ILLIQ-five most } \\
\text { illiquid stocks }\end{array}$ & $\begin{array}{l}\text { RCT-five most } \\
\text { liquid stocks }\end{array}$ & $\begin{array}{c}\text { ILLIQ-five most } \\
\text { liquid stocks }\end{array}$ \\
\hline & KOEI & VLEN & KRAS & ARNT \\
\hline & MAIS & INGR & ADPL & ADPL \\
\hline & ATGR & DLKV & INGR & KRAS \\
\hline & $\mathrm{ZABA}$ & ATPL & DDJH & PODR \\
\hline & VLEN & MAIS & ERNT & ATGR \\
\hline $\begin{array}{c}\text { Expected } \\
\text { portfolio return }\end{array}$ & 0.00064 & 0.00019 & -0.00079 & 0.00008 \\
\hline $\begin{array}{c}\text { Standard } \\
\text { deviation of } \\
\text { portfolio return }\end{array}$ & 0.01147 & 0.01456 & 0.01217 & 0.00808 \\
\hline
\end{tabular}

ILLIQ does not follow obligatory request that returns increase in illiquidity while RCV has the ability of taking into account the pressure of large variations in traded volume on return. RCT gives satisfactory results, making clear distinction between liquid and illiquid stocks. RCT in both cases, portfolio of 5 most illiquid stocks and portfolio of 10 most liquid stocks gives portfolios with expected return above expected return of CROBEX index and expected return of ILLIQ based illiquid portfolios. Paired samples t-test was performed for all combinations of portfolios of 5 stocks and portfolios of 10 stocks along with expected return of CROBEX index. Results of performed t-tests showed that there is no statistically significant difference in expected returns in case of all 4 portfolios of 5 stocks along with CROBEX index expected return, the same results were found in case of portfolios of 10 stocks. Only difference in expected returns which was confirmed is difference between return of RCT10 illiquid portfolio and return of RCT10 liquid portfolio (prob. 0.09). Major conclusion cannot be drawn due to limitations in number of observed stocks and portfolios but RCT due to these results can be observed as a liquidity measure which has potential to divide stocks in category where excess expected returns can be expected as a result of illiquidity and a category of stocks where excess expected returns cannot be expected

\section{Conclusions}

In this paper liquidity-based investment style using Relative Change in Turnover (RCT) and ILLIQ as measures of liquidity was tested. Equally weighted portfolios of liquid and illiquid stocks were composed on the basis of liquidity measurement. Returns of these portfolios were observed in the following one-year period. RCT measure tracks inconsistency of trading. Large changes in turnover between two trading days respective to trading turnover in observed period could produce possible pressure on stock price. Stocks that had larger traded volume during year had greater market liquidity or depth [14]. 
RCT5 and RCT10 based illiquidity portfolios gave larger returns in the following one-year period than ILLIQ5 and ILLIQ10 portfolios and CROBEX index. Although better, these expected returns were not significantly different. Under 10\% probability level is noticed difference between RCT10 illiquid portfolio return and RCT10 liquid portfolio return (prob. 0.09), difference between ILLIQ10 illiquid and ILLIQ liquid expected returns was not statistically significant (prob. 0.87). Returns of ILLIQ liquid and illiquid portfolio bring closer over time, meaning that effect of Illiquidity in ILLIQ based portfolios evaporates through time. This is noticed previously in [1] who concluded that the effect of ILLIQ on expected return is lower in the second half of the sample period than in the first half (sample is one year).

RCT portfolios outperformed market and ILLIQ5 and ILLIQ10 portfolios in out of sample period although they were not reconstructed at any time and had the same composition based on the result that came from observing RCT in previous one-year period. RCT10 illiquid portfolio had highest return $0.019 \%$ and RCT10 liquid portfolios had lowest return $-0.082 \%$. Results of RCT10 portfolios support assumption that expected returns are increasing in illiquidity. When this assumption is fulfilled an illiquidity measure can be considered as valid measure.

RCT based portfolios of illiquid stocks outperformed CROBEX index and had lower standard deviation compared to ILLIQ based portfolios of illiquid stocks but still higher standard deviation than CROBEX index. These differences between variances of mentioned portfolios were statistically significant in one month, two months, etc. until one-year period. These results are consistent with [14] who noticed that the returns of RCV [6] Quintile Five outperformed the JSE All Share Index (J203T) and also had a lower standard deviation compared to JSE All Share.

Further investigation of applicability of RCT as measure of illiquidity on underdeveloped markets is necessary. Special attention should be given to volatility and durability (persistence) of portfolio returns where portfolios are formed based on observing RCT and other illiquidity measures.

\section{Conflicts of Interest}

The author declares no conflicts of interest regarding the publication of this paper.

\section{References}

[1] Amihud, Y. (2002) Illiquidity and Stock Returns: Cross Section and Time Series Effects. Journal of Financial Markets, 5, 31-56. https://doi.org/10.1016/S1386-4181(01)00024-6

[2] Brennan, M.J. and Subrahmanyam, A. (1996) Market Microstructure and Asset Pricing: On the Compensation for Illiquidity in Stock Returns. Journal of Financial Economics, 41, 441-464. https://doi.org/10.1016/0304-405X(95)00870-K

[3] Dey, M.K. (2005) Turnover and Return in Global Stock Markets. Emerging Markets Review, 6, 45-67. https://doi.org/10.1016/j.ememar.2004.09.003 
[4] Pagano, M. (1989) Trading Volume and Asset Liquidity. The Quarterly Journal of Economics, 104, 255-274. https://doi.org/10.2307/2937847

[5] Chai, D., Faff, R. and Gharghori, F. (2010) New Evidence on the Relation between Stock Liquidity and Measures of Trading Activity. International Review of Financial Analysis, 19, 181-192. https://doi.org/10.1016/j.irfa.2010.02.005

[6] Vidović, J., Poklepović, T. and Aljinović, Z. (2014) How to Measure Illiquidity on European Emerging Stock Markets? Business Systems Research Journal, 5, 67-81. https://doi.org/10.2478/bsrj-2014-0020

[7] Mabuza, E. (2017) Illiquidity Premium in Asset Returns: An Empirical Analysis of Various Liquidity Measures to Determine the Best Measure of Liquidity on the Johannesburg Stock Exchange. Doctoral Dissertation, University of Pretoria, Pretoria.

[8] Datar, V.T., Naik, N.Y. and Radcliffe, R. (1998) Liquidity and Stock Returns: An Alternative Test. Journal of Financial Markets, 1, 203-219. https://doi.org/10.1016/S1386-4181(97)00004-9

[9] Aitken, M. and Comerton-Forde, C. (2003) How Should Liquidity Be Measured? Pacific-Basin Finance Journal, 11, 45-59. https://doi.org/10.1016/S0927-538X(02)00093-8

[10] Aitken, M.J. and Winn, R. (1997) What Is This Thing Called Liquidity? Working Paper, Securities Industry Research Centre of Asia-Pacific.

[11] Bekaert, G., Harvey, C.R. and Lundblad, C. (2007) Liquidity and Expected Returns: Lessons from Emerging Markets. Review of Financial Studies, 20, 1783-1831. https://doi.org/10.1093/rfs/hhm030

[12] Lesmond, D.A. (2005) Liquidity of Emerging Markets. Journal of Financial Economics, 77, 411-452. https://doi.org/10.1016/j.jfineco.2004.01.005

[13] Benić, V. and Franić, I. (2009) Stock Market Liquidity: Comparative Analysis of Croatian and Regional Markets. Financial Theory and Practice, 32, 477-498.

[14] Bogdan, S., Bareša, S. and Ivanović, S. (2012) Measuring Liquidity on Stock Market: Impact on Liquidity Ratio. Tourism and Hospitality Management, 18, 183-193.

[15] Vidović, J. (2013) Investigation of Stock Illiquidity on Central and South East European Markets in Naïve Portfolio Framework. Economic Thought and Practice, 22, 537-550.

[16] Stanković, J.Z. and Petrović, E. (2018) Liquidity Risk Implications for Market Risk Assessment in Emerging Markets. Journal of Contemporary Economic and Business Issues, 5, 5-23.

[17] Minović, J. and Živković, B. (2014) CAPM Augmented with Liquidity and Size Premium in the Croatian Stock Market. Economic Research Ekonomska Istraživanja, 27, 191-206. https://doi.org/10.1080/1331677X.2014.952107

[18] Minovic, J.Z. (2012) Liquidity of the Croatian Stock Market: An Empirical Analysis. Economic Research Ekonomska Istraživanja, 25, 776-802. https://doi.org/10.1080/1331677X.2012.11517533

[19] Vidović, J. and Aljinović, Z. (2009) Research on Stock Returns in Central and South-East European Transitional Economies. International Symposium on Operational Research, Nova Gorica, 237-246.

[20] Vidović, J., Poklepović, T. and Aljinović, Z. (2013b) On Illiquidity Measures on European Emerging Stock Markets. Proceedings of the 12 th International Symposium on Operational Research, Dolenjske Toplice, 311-316. 
Appendix. Observed Stocks

\begin{tabular}{|c|c|}
\hline Symbol & Issuer \\
\hline ARNT & Arena Hospitality Group d.d. \\
\hline ATPL & ATLANTSKA PLOVIDBA d.d. \\
\hline KOEI & KONČAR, d.d. \\
\hline KRAS & KRAŠ d.d. \\
\hline PODR & PODRAVKA d.d. \\
\hline RIVP & Valamar Riviera d.d. \\
\hline ZABA & Zagrebačkabankad.d. \\
\hline VLEN & BRODOGRADILIŠTE VIKTOR LENAC d.d. \\
\hline DLKV & Dalekovod, d.d. \\
\hline ERNT & ERICSSON NIKOLA TESLA d.d. \\
\hline ATGR & ATLANTIC GRUPA d.d. \\
\hline ADPL & AD PLASTIK d.d. \\
\hline ADRS2 & ADRIS GRUPA d.d. \\
\hline MAIS & MAISTRA d.d. \\
\hline INGR & INGRA d.d. \\
\hline OPTE & OT-OPTIMA TELEKOM d.d. \\
\hline $\mathrm{DDJH}$ & ĐURO ĐAKOVIĆ GRUPA d.d. \\
\hline HT & HT d.d. \\
\hline
\end{tabular}

Source: Prepared based on data from Zagreb Stock Exchange, available at:

https://www.zse.hr/default.aspx?id=44101\&index=CROBEX www.zse.hr (16.11.2018) 